\title{
The influence of Occupation and Teamwork on the Successful Use of the WHO Surgical Checklist: Experiences of Swedish Healthcare Professionals
}

\author{
Krupic $\mathbf{F}^{1,2}$ \\ ${ }^{1}$ Department of Anaesthesiology, Institute of Clinical Sciences, Sahlgrenska Academy, \\ University of Gothenburg, Gothenburg, Sweden \\ ${ }^{2}$ Department of Orthopaedics, Institute of Clinical Sciences, Sahlgrenska Academy, \\ University of Gothenburg, Gothenburg, Sweden \\ Corresponding Author: Krupic F
}

\begin{abstract}
Background: Every year, some 300 million operations are performed around the world, with approximately 700,000 in Sweden. This represents about one surgical procedure per 25 people. All these operations are not free of risk. The safety of patients can be enhanced by teamwork, good communication and checklists ensuring adherence to safety routines. The aim of the present study was to describe the experience of Swedish healthcare professionals of using the WHO surgical checklist, with special emphasis on different occupations and teamwork.

Methods: A descriptive cross-sectional statistical study, including healthcare professionals from two departments at a university hospital in the western part of Sweden, was conducted.

Data were collected from one hundred and ninety-six healthcare professionals, using a selfadministered questionnaire that contained 12 questions. The Mantel-Haenszel and Pearson $\chi^{2}$ tests were used for ordered and unordered categorical variables.

Results: One hundred and ninety-six healthcare professionals, aged 21-73, and 6 different categories with 5-25 years experiences participated. Regarding the usage of the checklist at different departments, the biggest different was about responsibility to implementation of the checklist $(p=0,001)$, using the checklist in the emergency situations $(p=0.04)$, if the checklist improve patient's safety $(\mathrm{p}=0.04)$, and if the list has been completed correctly $(\mathrm{p}=0,006)$. Regarding the training for using the checklist, anaesthetist nurses were most negative with $75,5 \%$, and the operating nurses were most positive with $39.2 \%$. 66,0\% of nurse anaesthetists, the checklist was adapted to the department. Majority of all the occupations thought that the checklist improved patients safety, and that the checklist had been correctly completed.

Conclusion: Different departments and different occupations experience difficulties using the checklist in the Swedish healthcare system. More research is needed to investigate the experiences of healthcare professionals, whether different occupations report differently about using the checklist and whether teamwork is influenced by using the checklist. A further understanding of the checklist and its importance, as well as its content, could increase the safety of patients due to improved compliance.
\end{abstract}

Keywords: WHO checklist, surgery, occupation, teamwork questionnaire, research

\section{INTRODUCTION}

Surgical procedures are without doubt an extremely important aspect of modern medicine (1). Every year, some 300 million operations are performed around the world, representing approximately one surgical procedure per 25 people. However, the safety of patients in the operating room can be enhanced by teamwork, good communication and checklists ensuring 
adherence to safety routines (2). The Swedish Patient Safety Act (3) promotes patient safety by prescribing that healthcare providers must ensure that work is undertaken with a high regard for patient safety. Surgery is highly technical and complex, with teams comprising many different professions working together, and there is a high level of risk of error $(2,4)$. There are two important factors when it comes to promoting patient safety: communication and effective teamwork (5). Teamwork is defined as a smaller group of people with different skills who work towards a common goal where everyone is dependent on each other. The team members have complementary skills and the same responsibility. The number of people in the team may vary, but in order to keep the team together, working towards the common goal and purpose, it is easier if the number of people is as low as possible (6). Each team in an operating room consists of an anaesthesiologist, operation nurse, anaesthesia nurse, surgeon, and an assistant nurse. Each occupational category contributes its competence and works towards the common goals that consist of taking care of the patient and carrying out the day's surgical programme. The competence of all the occupational categories is an important part of the team. All the categories in the team have the task within their respective professional area of leading, prioritising and co-ordinating care work around the patient. In a previous study, the authors demonstrated the importance of the healthcare professionals in the operating room feeling familiar with the members of the team. Shared responsibility in the team made it possible to detect risks to the patient and prevent mistakes. Difficulties arise when team members are often replaced due to the needs of the business (7). The World Health Organisation(8) promotes the WHO surgical safety checklist (WHOSSC) worldwide to improve the safety of patients. The WHOSSC consists of 19 separate items that should be checked at three different points in time: the "sign-in", before the induction of anaesthesia; the "time-out", before a skin incision is made; and the "sign-out", at the end of the procedure. The use of the WHOSSC and other checklists has led to improved patient outcomes, adherence to standard care procedures and improved teamwork during surgeries (9-11). A pilot study, performed after the introduction of the WHO SSC to assess the effect of implementation, showed a reduction in the surgical complication rate, surgical site infection, unexpected re-operation, and death rate in hospital (12). Another study, showing improvements in patient identification and surgical site confirmation, emphasised that a better understanding of each team member's role helped to produce better communication and teamwork (13). Other studies have reported contradictory results. Urbach et al. (14) investigated the effect of surgical safety checklists at 101 hospitals. They compared mortality data, surgical complications and re-admissions before and after the implementation of a checklist and did not find any significant differences. Lübbeke et al. (15) also reported no effect on 30-day mortality, unplanned critical care admissions and unplanned repeat surgery. Communication and teamwork in the operating team must be equal and without hierarchy in order to be effective (16). Several studies show that different healthcare categories value and perceive collaboration and communication with others differently (17). Among other things, it is emphasised that the focus should be on the checklist and not on the different professions and that the control is not based on how well or poorly the work is done. It may also be that the checklist is seen as a cross-border procedure and promotes interaction within the team $(13,18-20)$. However, we are not aware of any previously published research describing the impact of different occupations and teamwork on using the WHO checklist in the operating theatre. The aim of the present study was therefore to describe the experience of Swedish healthcare 
professionals when using the WHO surgical checklist, with special emphasis on different occupations and teamwork.

\section{Theoretical framework}

According to Eriksson's theory (21), the caring science is defined by its ontology and human orientation. Caring is something human by nature and it is expressed through tending, playing and learning in order to attain integrity and wholeness that is compatible with bearable suffering $(22,23)$. Tending represents concrete qualitative characteristics such as a feeling of being welcome, confidence, hope and safety. Playing includes the characteristic hallmarks of spontaneity, imagination, creativity, desires and wishes, while learning encompasses development, constant growth and change (21, 22). Caring is ontological and an expression of caritas; it is the innermost being of caring that we work to bring to the fore. Professional caring is based on natural caring and is constituted by the idea of motherliness (21-23), which implies the genuine, universal, spontaneous and unconditional love and charity that characterise caritative caring. The human being is seen as an integrated entity of body, soul and spirit, where health and suffering are prevailing conditions in life. Health consists of movements between the actual and the potential in the human being's process of being, where suffering is seen as a basic category of caring. Suffering has many facets and characteristics, has no distinct reason or definition and lacks an explicit language. Suffering has no meaning, but, by reconciliation, meaning can be ascribed to it. Through reconciliation, the feeling of wholeness and holiness is re-created. Ontologically, every human being is fundamentally seen as longing for and striving for wholeness and integration $(21,23)$.

\section{MATERIAL AND METHOD Sample and settings}

A quantitative, statistical method study with a descriptive study design was performed at one university hospital in the western part of Sweden. The study was conducted between September 2018 and March 2019. The healthcare professionals who reported using the WHO checklist at least five times, those who were employed at the hospital and those who were willing to participate in the study were included. The employees who were hired as extra staff and those that were employed at the hospital but declined participation in the study were excluded from the study. Assistant nurses, nurse anaesthetists, operating nurses, anaesthesiologists, surgeons and obstetric surgeons were eligible to participate. Of 248 healthcare professionals, one hundred and ninety-six healthcare professionals (79\%) completed the questionnaire. The data in this study were collected from healthcare professionals working on two different wards; Workplace 1 (surgery for women's diseases) and Workplace 2 (surgery for abdominal complaints).

\section{The questionnaire}

The study questionnaire was conducted by the authors to realise the aim of this study, based on the author's own experience of surgery and the literature on implementing and using the WHOSSC. The questionnaire was validated by one nurse anaesthetist, one operating nurse, one surgeon in obstetrics and one anaesthesiologist, using the test-retest statistical method. These individuals were included in the present study.

The questionnaire included the following issues:

- The age, gender, occupation, work experience and workplace of the healthcare professionals

- Whether they had completed education/training in using the WHO checklist at their department

- Had the WHO checklist been adapted to their department?

- Was it clear who was responsible for ensuring that the WHO checklist was implemented? 
Krupic F. The influence of occupation and teamwork on the successful use of the WHO surgical checklist: experiences of Swedish healthcare professionals.

- Who was responsible for using the WHO checklist before surgery?

- How often did they think the WHO checklist was used in emergency situations?

- Does the WHO checklist improve patient safety?

- Does the WHO checklist improve teamwork?

- How often has the WHO checklist been completed correctly?

\section{Data collection}

The questions were sent beforehand to both the head doctor and nurse for approval. The healthcare professionals were then given the opportunity to answer the questions. Both written and verbal information regarding the study and the questionnaire that was on paper was given to the healthcare professionals. The questionnaire was distributed by the author of the study to the surgical wards. The healthcare professionals were given two weeks to complete the questionnaire which took about five to eight minutes to complete and the questions were answered anonymously. The participants were also reminded twice via email.

\section{Data analysis}

In the present study, the MannWhitney U-test was used to compare the groups in terms of continuous variables, Fisher's exact test for dichotomous variables, the Mantel-Haenszel chi-square test for ordered categorical variables and the Pearson chi-square test for unordered categorical variables. Descriptive statistics for continuous variables are given, while the means, standard deviations, medians, the $25 \%$ quartile, the $75 \%$ quartile, minimum and maximum and numbers and percentages are given for categorical variables. All the tests were two-sided and conducted at the $5 \%$ level of significance. Statistical analysis was performed using the SAS System for Windows Version 9.4, Cary, NC, USA.

\section{Ethical considerations}

Under Swedish law (Swedish Health Care Act), it was not necessary to apply to the ethics committee, as there was no physical intervention and no information on individual health issues in the study (24). The World Medical Association Declaration of Helsinki (25) was followed carefully. The healthcare professionals' identities were protected, whereby their names and personal identity numbers were not given in any recordings or publications.

\section{RESULT \\ Baseline characteristics}

Table 1. Characteristics of healthcare professionals
\begin{tabular}{|l|l|}
\hline Gender & Number \\
\hline Male & 47 \\
\hline Female & 149 \\
\hline Total & 196 \\
\hline Workplace & \\
\hline Workplace 1 & 107 \\
\hline Workplace 2 & 89 \\
\hline Total & 196 \\
\hline Occupation & \\
\hline Anaesthesiologist & 36 \\
\hline Obstetrics & 23 \\
\hline Surgeon & 17 \\
\hline Anaesthetist nurse & 38 \\
\hline Surgical nurse & 39 \\
\hline Assistant nurse & 43 \\
\hline Total & 196 \\
\hline Age (years) & \\
\hline $21-30$ & 31 \\
\hline $31-40$ & 43 \\
\hline $41-50$ & 55 \\
\hline $51-60$ & 49 \\
\hline$\geq 60$ & 21 \\
\hline Total & 196 \\
\hline Experience (years) & \\
\hline$\leq 5$ & 54 \\
\hline $6-10$ & 30 \\
\hline $11-15$ & 22 \\
\hline $16-20$ & 23 \\
\hline$\geq 20$ & 67 \\
\hline Total & 196 \\
\hline & \\
\hline
\end{tabular}

A total of one hundred and ninetysix healthcare professionals, 47 men and 149 women, participated in the present study. The mean age of the men was 40.2 years and the mean age of the women was 42.4 years. One hundred and seven healthcare professionals worked at Workplace number 1 and 89 at Workplace number 2 . The majority of the healthcare professionals were between 40 and 50 years old and most of the healthcare professionals 
Krupic F. The influence of occupation and teamwork on the successful use of the WHO surgical checklist: experiences of Swedish healthcare professionals.

in this study had worked for $\leq 5$ years and more than 20 years (Table 1 ).

\section{Use of the WHO checklist regarding the different departments}

Table 2. Use of the WHO checklist regarding the different departments

\begin{tabular}{|c|c|c|c|}
\hline Variables/questions & \begin{tabular}{|l|} 
Workplace (1) \\
$(\mathrm{n}=107)$
\end{tabular} & $\begin{array}{l}\text { Workplace (2) } \\
(\mathrm{n}=89)\end{array}$ & p-value \\
\hline \multicolumn{4}{|c|}{ Have you completed education/training on using the WHO checklist at your department? } \\
\hline Yes & $36(33.6 \%)$ & $34(38.2 \%)$ & \\
\hline No & $71(66.4 \%)$ & $55(61.8 \%)$ & 0.613 \\
\hline \multicolumn{4}{|c|}{ Has the WHO checklist been adapted to your department? } \\
\hline Yes & $65(60.7 \%)$ & $62(69.7 \%)$ & \\
\hline No & $42(39.3 \%)$ & $27(30.3 \%)$ & 0.251 \\
\hline \multicolumn{4}{|c|}{ Is it clear who is responsible for ensuring that the WHO checklist is implemented? } \\
\hline Surgeon & $4(3.7 \%)$ & $19(21.3 \%)$ & \\
\hline Anaesthesiologist & $2(1.9 \%)$ & $0(0.0 \%)$ & \\
\hline Anaesthetist nurse & $11(10.3 \%)$ & $7(7.9 \%)$ & \\
\hline Surgical nurse & $19(17.8 \%)$ & $7(7.9 \%)$ & \\
\hline Assistant nurse & $71(66.4 \%)$ & $56(62.9 \%)$ & 0.001 \\
\hline \multicolumn{4}{|c|}{ Do you know who is responsible for using the WHO checklist before surgery? } \\
\hline Yes & $11(10.3 \%)$ & $10(11.2 \%)$ & \\
\hline No & $96(89.7 \%)$ & $74(83.1 \%)$ & \\
\hline Don’t know & $0(0.0 \%)$ & $5 \% .6 \%)$ & 0.360 \\
\hline \multicolumn{4}{|c|}{ How often do you think the WHO checklist is used in emergency situations? } \\
\hline All the time & $71(66.4 \%)$ & $44(49.4 \%)$ & \\
\hline Often (every second operation) & $32(29.9 \%)$ & $39(43.8 \%)$ & \\
\hline Seldom (every fourth operation) & $2(1.9 \%)$ & $6(6.7 \%)$ & \\
\hline Never & $2(1.9 \%)$ & $0(0.0 \%)$ & 0.045 \\
\hline \multicolumn{4}{|c|}{ Does the WHO checklist improve patient safety? } \\
\hline Totally agree & $76(71.0 \%)$ & $70(78.7 \%)$ & \\
\hline Partly agree & $17(15.9 \%)$ & $17(19.1 \%)$ & \\
\hline Doubtful & $12(11.2 \%)$ & $1(1.1 \%)$ & \\
\hline Do not agree at all & $2(1.9 \%)$ & $1(1.1 \%)$ & 0.047 \\
\hline \multicolumn{4}{|c|}{ Does the WHO checklist improve teamwork? } \\
\hline Totally agree & $26(24.3 \%)$ & $45(50.6 \%)$ & \\
\hline Partly agree & $77(72.0 \%)$ & $36(40.4 \%)$ & \\
\hline Doubtful & $3(2.8 \%)$ & $6(6.7 \%)$ & \\
\hline Do not agree at all & $1(0.9 \%)$ & $2(2.2 \%)$ & 0.028 \\
\hline \multicolumn{4}{|c|}{ How often has the WHO checklist been completed correctly? } \\
\hline All the time & $30(28.0 \%)$ & $45(50.6 \%)$ & \\
\hline Often (every second operation) & $64(59.8 \%)$ & $37(41.6 \%)$ & \\
\hline Seldom (every fourth operation) & $13(12.1 \%)$ & $6(6.7 \%)$ & \\
\hline Never & $0(0.0 \%)$ & $1(1.1 \%)$ & 0.006 \\
\hline
\end{tabular}

The result of the survey and a comparison of the answers between Workplace 1 and Workplace 2 are presented in Table 2. There was no difference between the workplaces in terms of education regarding the use of the WHO checklist, where the majority at both workplaces had not completed an education (66.4\% compared with $61.8 \%, \mathrm{p}=0.61$ ). The WHO checklist had been adapted at the majority of the departments at which the respondents worked $(60.7 \%$ compared with $69.7 \%$, p= 0.25). According to most healthcare professionals, the assistant nurses were responsible for ensuring that the WHO checklist was implemented, However, this perception differed significantly between workplaces $(\mathrm{p}=0.0010)$, as a larger proportion at Workplace 2 believed that the surgeon was responsible, while it is noteworthy that a larger proportion at Workplace 1 believed that the operating nurse was responsible. Regarding the responsibility for using the WHO checklist before surgery, most of the healthcare professionals stated that they did not know who was responsible. In general, 170 (86.5\%) of all the healthcare professionals answered NO to the question asking if they knew who was responsible for using the WHO checklist. Only 21 (10.5\%) of them knew who was responsible for ensuring that the WHO checklist was used. The number of respondents who did not know who was responsible for using the checklist before surgery was 5 (3.0\%). Regarding the question about the usage frequency of the checklist in emergency situations, the 
Krupic F. The influence of occupation and teamwork on the successful use of the WHO surgical checklist: experiences of Swedish healthcare professionals.

respondents were able to reply always, often, seldom or never. Most respondents answered, "all the time"; 115 (57.9\%) answered "all the time", 71 (37.4\%) "often" and eight (4.7\%) "seldom". Two (1.9\%) of the healthcare professionals answered "never" to this question (Table 2). There was a significant difference $(p=0.045)$ between the groups, where a larger proportion at Workplace 1 (66.4\%) answered "all the time" compared with $49.4 \%$ at Workplace 2. There was also a significant difference in the answers to the question about whether the WHO checklist improves patient safety. The majority of the healthcare professionals answered positively, but $3 \%$ of them answered the question negatively (2 (1.9\%) compared with 1 (1.1\%), $\mathrm{p}=0.047$. Regarding the question of whether the WHO checklist improves teamwork, most of the healthcare professionals answered they they totally agreed, but even here $3.1 \%$ of the respondents stated that the checklist does not improve teamwork, 1 (0.9\%) compared with 2 (2.2\%), $\mathrm{p}=0.028$. The number of respondents who stated that the checklist had been completed correctly often came from Workplace 1, 64 (59.8\%), while the majority of the healthcare professionals at Workplace 2 stated that it was used all the time, 45 (50.6\%). Even in this question, there was a significant difference between the workplaces, $0(0.0 \%)$ compared with 1 (1.1\%), $\mathrm{p}=0.0061$, Table 2 .

\section{Use of the WHO checklist regarding the different occupations}

\begin{tabular}{|c|c|c|c|c|}
\hline Variables/questions & $\begin{array}{l}\text { Doctors } \\
(\mathrm{n}=37)\end{array}$ & $\begin{array}{l}\text { Anaesthetist nurses } \\
(\mathrm{n}=53)\end{array}$ & $\begin{array}{l}\text { Operation nurses } \\
(\mathrm{n}=51)\end{array}$ & $\begin{array}{l}\text { Assistant nurses } \\
(\mathrm{n}=55)\end{array}$ \\
\hline \multicolumn{5}{|c|}{ Have you completed education/training on using the WHO checklist in your department? } \\
\hline Yes & $17(45.9 \%)$ & $13(24.5 \%)$ & $20(39.2 \%)$ & $20(36.4 \%)$ \\
\hline No & $20(54.1 \%)$ & $40(75.5 \%)$ & $31(60.8 \%)$ & $35(63.6 \%)$ \\
\hline \multicolumn{5}{|c|}{\begin{tabular}{|l|l|l|} 
Has the WHO checklist been adapted to your department? & \\
\end{tabular}} \\
\hline Yes & $26(70.3 \%)$ & $35(66.0 \%)$ & $32(62.7 \%)$ & $34(61.8 \%)$ \\
\hline No & $11(29.7 \%)$ & $18(34.0 \%)$ & $19(37.3 \%)$ & $21(38.2 \%)$ \\
\hline \multicolumn{5}{|c|}{ Is it clear who is responsible for ensuring that the WHO checklist is implemented? } \\
\hline Surgeon & $6(16.2 \%)$ & $6(11.3 \%)$ & $2(3.9 \%)$ & $9(16.4 \%)$ \\
\hline Anaesthesiologist & $0(0.0 \%)$ & $1(1.9 \%)$ & $1(2.0 \%)$ & $0(0.0 \%)$ \\
\hline Anaesthetist nurse & $7(18.9 \%)$ & $4(7.5 \%)$ & $4(7.8 \%)$ & $3(5.5 \%)$ \\
\hline Surgical nurse & $4(10.8 \%)$ & $5(9.4 \%)$ & $12(23.5 \%)$ & $5(9.1 \%)$ \\
\hline Assistant nurse & $20(54.1 \%)$ & $37(69.8 \%)$ & $32(62.7 \%)$ & $38(69.1 \%)$ \\
\hline \multicolumn{5}{|c|}{ Do you know who is responsible for using the WHO checklist before surgery? } \\
\hline Yes & $1(2.7 \%)$ & $6(11.3 \%)$ & $5(9.8 \%)$ & $9(16.4 \%)$ \\
\hline No & $34(91.9 \%)$ & $47(88.7 \%)$ & $44(86.3 \%)$ & $45(81.8 \%)$ \\
\hline Don't know & $2(5.4 \%)$ & $0(0.0 \%)$ & $2(3.9 \%)$ & $1(1.8 \%)$ \\
\hline \multicolumn{5}{|c|}{ How often do you think the WHO checklist is used in emergency situations? } \\
\hline All the time & $24(64.9 \%)$ & $37(69.8 \%)$ & $29(56.9 \%)$ & $25(45.5 \%)$ \\
\hline Often (every second operation) & $13(35.1 \%)$ & $13(24.5 \%)$ & $19(37.3 \%)$ & $26(47.3 \%)$ \\
\hline Seldom (every fourth operation) & $0(0.0 \%)$ & $2(3.8 \%)$ & $2(3.9 \%)$ & $4(7.3 \%)$ \\
\hline Never & $0(0.0 \%)$ & $1(1.9 \%)$ & $1(2.0 \%)$ & $0(0.0 \%)$ \\
\hline \multicolumn{5}{|c|}{ Does the WHO checklist improve patient safety? } \\
\hline Totally agree & $33(89.2 \%)$ & $39(73.6 \%)$ & $34(66.7 \%)$ & $40(72.7 \%)$ \\
\hline Partly agree & $3(8.1 \%)$ & $8(15.1 \%)$ & $12(23.5 \%)$ & $11(20.0 \%)$ \\
\hline Doubtful & $0(0.0 \%)$ & $5(9.4 \%)$ & $4(7.8 \%)$ & $4(7.3 \%)$ \\
\hline Do not agree at all & $1(2.7 \%)$ & $1(1.9 \%)$ & $1(2.0 \%)$ & $0(0.0 \%)$ \\
\hline \multicolumn{5}{|l|}{ Does the WHO checklist improve teamwork? } \\
\hline Totally agree & $22(59.5 \%)$ & $16(30.2 \%)$ & $14(27.5 \%)$ & $19(34.5 \%)$ \\
\hline Partly agree & $14(37.8 \%)$ & $36(67.9 \%)$ & $33(64.7 \%)$ & $30(54.5 \%)$ \\
\hline Doubtful & $1(2.7 \%)$ & $1(1.9 \%)$ & $3(5.9 \%)$ & $4(7.3 \%)$ \\
\hline Do not agree at all & $0(0.0 \%)$ & $0(0.0 \%)$ & $1(2.0 \%)$ & $2(3.6 \%)$ \\
\hline \multicolumn{5}{|c|}{ How often has the WHO checklist been completed correctly? } \\
\hline All the time & $16(43.2 \%)$ & $17(32.1 \%)$ & $15(29.4 \%)$ & $27(49.1 \%)$ \\
\hline Often (every second operation) & $16(43.2 \%)$ & $29(54.7 \%)$ & $32(62.7 \%)$ & $24(43.6 \%)$ \\
\hline Seldom (every fourth operation) & $5(13.5 \%)$ & $6(11.3 \%)$ & $4(7.8 \%)$ & $4(7.3 \%)$ \\
\hline Never & $0(0.0 \%)$ & $1(1.9 \%)$ & $0(0.0 \%)$ & $0(0.0 \%)$ \\
\hline
\end{tabular}

Table 3 shows the results of the questionnaire and a comparison of the answers between the four different occupations. In the first question regarding training for using the checklist, anaesthetist nurses accounted for the highest percentage 
in a negative direction, with $75.5 \%$. The group with the most positive answers were the operating nurses, with $39.2 \%$. According to $35(66.0 \%)$ of nurse anaesthetists, the checklist was adapted to the department. Most negative answers to this question were given by assistant nurses, 21 (38.2\%), Table 3. Most healthcare professionals believed that the assistant nurses were responsible for ensuring that the WHOSSC checklist was implemented. This included most doctors, 20 (54.1\%) compared with assistant nurses, 38 (69.1\%). With regard to the responsibility for using the checklist before surgery, almost all the doctors, $91.9 \%$, and nurse anaesthetists, $88.7 \%$, answered no to this question. The occupational group who knew who was responsible for using the WHOSSC before surgery was the assistant nurses, with $16.4 \%$. In the question about the usage frequency of the checklist in emergency situations, the healthcare professionals had the opportunity to answer always, often, seldom or never.

However, two $(3.9 \%)$ of the nurse anaesthetists answered "never" to this question (Table 2). The majority of all the occupations thought that the checklist improved patient safety. Most of the doctors totally agreed that the list improves patient safety (89.2\%), but three of them (6.6\%) did not agree that the checklist improves patient safety. A little more than half of the doctors thought that the checklist improves teamwork 22 (59.5\%), but three (5.6\%) of all healthcare professionals emphasised that they did not agree with this (Table 3). According to $27(49.1 \%)$ of all the assistant nurses, the WHO checklist had been correctly completed, while one (1.9\%) nurse anaesthetist stated that the checklist is never completed.

\section{DISCUSSION}

The aim of the present study was to describe the experience of Swedish healthcare professionals in using the WHO surgical checklist, with special emphasis on different occupations and teamwork. The choice of method in the study was based on the collection of answers from a questionnaire, in order to obtain a large number of respondents, as well as determining the purpose of the study, in a short period, Moreover, the questionnaire gave the authors the opportunity to base some parts of it on the checklist, which resulted in the aim being realised. The questionnaire consisted of short questions, meaning that no long explanations were given that could have resulted in the respondent not reading the whole question. This also increased the validity (26). An effort was made to give uniform information to the participants about the questionnaire and data collection at the various operating units and hospitals. This is the reason why as many as $79 \%$ or 196 of all the staff answered the questionnaire, which is an excellent response rate. Regarding the study participants' demographic data, most of them had between five- and twenty-years' experience. Patient safety in surgery may be endangered when there is a lack of experience, or if the staff are elderly. Surgical safety checklists are designed to increase good clinical practice and improve surgical safety, by ensuring greater compliance with standards and supporting teamwork and communication. The healthcare professionals mentioned that their training in using the checklist was not sufficient. These results showed that most of the healthcare professionals had not received any training in using the checklist, only $38.2 \%$ of the staff at Workplace 2, while the staff with most training in using the checklist were the doctors with $45.9 \%$. The results in our study are in line with those in a study of nurse anaesthetists in Sweden, where it was shown that only $43 \%$ of the nurses had taken part in training on using the checklist (27). Moreover, other studies show that the checklist was not followed and implemented correctly, possibly because the healthcare professionals did not have enough knowledge of its use, and it was necessary to train them in how the list is structured $(28,29)$. Another study from Sweden was 
performed as an intervention study, with the aim of evaluating the safety climate in the operating room setting before and after an intervention and using the revised WHO checklist to improve teamwork. Despite the healthcare professionals' statement regarding teamwork as being very important for patient safety, there were different perceptions of good teamwork between the healthcare professionals. In that study, the authors showed that the education, intervention and a revised checklist did not influence the teamwork climate (30). Eriksson's theory (21-23) of human caring should be more widely used in nursing practice. However, given the current state of the Swedish healthcare system, with a few basic problems that are "shaking" the healthcare system, this is difficult in some ways. Our results show the disparity in the work experience of the respondents in our study; the shift of two generations employed in the healthcare system, a general shortage of Swedish health workforce and an increase in workers employed privately and hired in the Swedish health system are just some of the fundamental difficulties which are visible in the healthcare system. The work tasks of the employees are the same, there are fewer workers, or they are employed on a part-time basis, all of which can lead to the prioritisation of other things that would be done in a completely different way in more normal situations. Regarding the adaptation of the checklist to the department, the results of our study showed that the answers were a little better. The answers to the question were more positive than negative and the highest percentage in this group (69.7\%) comprised Workplace 2 and anaesthetist nurses (66.0\%). The healthcare professionals in this questionnaire were not certain who was responsible for making sure that the checklist was implemented. They all mentioned assistant nurses (66.4\% compared with $69.8 \%, \mathrm{p}=0.001$ ) and the majority of all the occupations did not know who was responsible for using the checklist before surgery $(89.7 \%$ compared with
91.9\%). It is very important to note that the majority of those who were not aware of this were the doctors. These findings contrast with those from another study conducted in Sweden (27), where the authors reported that the nurse anaesthetists thought that the surgeon should be responsible for starting and implementing the checklist. However, our study is in line with that study in another respect, which showed that this did not work in practice, because it is often the assistant nurse who implements and starts the checklist. In this case, the hierarchy and organisation in the healthcare system may be visible. Most of the respondents in the study, regarding the question about responsibility for using the list, as well as who was responsible for the list before surgery, answered that it was the assistant nurses. It is worrying and extremely surprising that almost $92 \%$ of the physicians replied that they did not know who was responsible for implementing the list before the operation began. The answer to this question is inversely proportional and shows that, although assistant nurses are the least educated, they offered the best and most acceptable answer to this question. Another part of this may be that the interprofessional communication does not work, or that different professions operate on different fronts. If this is the case, the present study is in line with other studies which show that different occupations communicate more easily with similar occupations than with others $(17,31)$. The difficulties involved in interprofessional communication may reduce the efficacy of the teamwork (32, 33). In emergency situations, $66.4 \%$ of the healthcare professionals reported using the checklist at Workplace 1 , while $1.9 \%$ professionals stated that the checklist was never used. Of all the anaesthetist nurses, $69.8 \%$ claimed that the checklist was always used, but 3.9\% of the healthcare professionals stated that the checklist was never used, which is worrying. The findings in this study contrast with those in two previous studies where it was stated that the use of the checklist in 
emergency situations and in paediatric emergency plastic surgery corresponded at both stages regarding the individual stages and ranged from $85 \%$ for signing-in to $98 \%$ for time-out (34). A study of emergency laparotomies revealed that fewer patients were scheduled for an elective laparotomy and that the use of the checklist was also less frequent among them in comparison to emergency laparotomies, in more highly developed countries (35). Several important findings to emerge from the analysis in the present study were unexpected and surprising. At departmental level and in terms of increasing patient safety by using the checklist, $15.3 \%$ were doubtful and did not agree with this. At occupational level, the situation was even worse, as $31.1 \%$ were doubtful. It was no better regarding the question about improving teamwork and using the checklist, $12.6 \%$ compared with $23.4 \%$. The most alarming and worrying point in the present study is that as many as $41.8 \%$ of the healthcare professionals think that the use of the WHO checklist does not end correctly after the end of the operating process. The results in our study show once again that the suboptimal use of the checklist and the use of the checklist by healthcare professionals who are busy with other things at a given time may cause the checklists to have a negative impact on the function of the team and influence teamwork. The difficulties and obstacles pointed out by healthcare professionals should be anticipated as strategically limiting prior to the implementation of the WHO checklists (36). Regardless of the positive or negative outcome of using the WHO checklist, this is an important component of the Swedish healthcare system. However, the use of the list requires healthcare professionals who are currently in short supply in the healthcare system.

\section{Study limitations}

There are limitations to the study. First, the principal investigator in the study and the person who conducted the survey are employed in the same department as the respondents, which may have caused the respondents to answer the questions more cautiously than usual. Secondly, the survey was conducted during working hours, which may have caused increased stress and reduced concentration among the respondents and, thirdly, despite the large number of respondents answering the survey, the results of our study cannot be used generally in a wider area of Sweden or Europe.

\section{CONCLUSION}

The findings in this study indicate that different departments and different occupations experience difficulties using the checklist in today's Swedish healthcare system. Most of the healthcare professionals missed training in using the checklist and, according to most of them, regarding the checklist for surgery, it is the assistant nurse who must ensure that the checklist is implemented. The healthcare professionals did not know who was responsible for using the checklist. The responses regarding the use of the checklist in emergencies and whether it improves patient safety and teamwork were no better. Almost half the healthcare professionals believe that the use of the checklist does not end correctly after the operation is completed. More research is needed to investigate the experiences of healthcare professionals, whether different occupations report differently about using the checklist and whether teamwork is influenced positively or negatively by using the checklist. A further understanding of the checklist and its importance, as well as its content, could increase the safety of patients due to improved compliance.

\section{Acknowledgement: None \\ Conflict of Interest: None \\ Source of Funding: None \\ Ethical Approval: Approved}

\section{REFERENCES}

1. Weiser TG, Regenbogen SE, Thompson KD, Haynes AB, Lipsitz SR, Berry WR, et al. An estimation of the global volume of 
Krupic F. The influence of occupation and teamwork on the successful use of the WHO surgical checklist: experiences of Swedish healthcare professionals.

surgery: a modelling strategy based on available data. Lancet. 2008;372(9633):13944.

2. Edberg A-K, Ehrenberg A, Friberg F, Wallin L, Wijk H, Öhlén J. Omvårdnad på avancerad nivå: kärnkompetenser inom sjuksköterskans specialistområden: Studentlitteratur; 2013.

3. Sweden Ro. Patientsäkerhetslag (2010:659) Stockholm: Socialdepartementet; 2010 [updated 2021:739. Available from: https://www.riksdagen.se/sv/dokumentlagar/dokument/svenskforfattningssamling/patientsakerhetslag2010659_sfs-2010-659.

4. Lepp M. Sjuksköterskans kärnkompetenser. Andra uppl) Stockholm. 2013.

5. Jones C, Durbridge M. Culture, silence and voice: the implications for patient safety in the operating theatre. Journal of perioperative practice. 2016;26(12):281-4.

6. Katzenbach JR. The wisdom of teams : creating the high-performance organization. Smith DK, editor. Boston, Mass.: Boston, Mass. : Harvard Business School Press; 1993.

7. Silén-Lipponen $M$, Tossavainen $K$, Turunen $\mathrm{H}$, Smith A. Potential errors and their prevention in operating room teamwork as experienced by Finnish, British and American nurses. International journal of nursing practice. 2005;11(1):21-32.

8. Safety WHOP, World Health O. Implementation manual WHO surgical safety checklist 2009 : safe surgery saves lives. Geneva: World Health Organization; 2009.

9. Buzink SN, van Lier $\mathrm{L}$, de Hingh $\mathrm{IH}$, Jakimowicz JJ. Risk-sensitive events during laparoscopic cholecystectomy: the influence of the integrated operating room and a preoperative checklist tool. Surgical endoscopy. 2010;24(8):1990-5.

10. de Vries EN, Prins HA, Crolla RM, den Outer AJ, van Andel G, van Helden SH, et al. Effect of a comprehensive surgical safety system on patient outcomes. New England Journal of Medicine. 2010;363(20):1928-37.

11. Russ S, Rout S, Sevdalis N, Moorthy K, Darzi A, Vincent C. Do safety checklists improve teamwork and communication in the operating room? A systematic review. Annals of surgery. 2013;258(6):856-71.

12. Haynes AB, Weiser TG, Berry WR, Lipsitz SR, Breizat A-HS, Dellinger EP, et al. A surgical safety checklist to reduce morbidity and mortality in a global population. New England journal of medicine. 2009; 360(5): 491-9.

13. Takala R, PAUNIAHO SL, Kotkansalo A, Helmiö P, Blomgren K, Helminen M, et al. A pilot study of the implementation of WHO S urgical $\mathrm{C}$ hecklist in $\mathrm{F}$ inland: improvements in activities and communication. Acta anaesthesiologica Scandinavica. 2011;55(10):1206-14.

14. Urbach DR, Govindarajan A, Saskin R, Wilton AS, Baxter NN. Introduction of surgical safety checklists in Ontario, Canada. N Engl J Med. 2014;370:1029-38.

15. Lübbeke A, Hovaguimian F, Wickboldt N, Barea C, Clergue F, Hoffmeyer P, et al. Effectiveness of the surgical safety checklist in a high standard care environment. Medical care. 2013:425-9.

16. Fourcade A, Blache J-L, Grenier C, Bourgain J-L, Minvielle E. Barriers to staff adoption of a surgical safety checklist. BMJ quality \& safety. 2012;21(3):191-7.

17. Makary MA, Sexton JB, Freischlag JA, Holzmueller CG, Millman EA, Rowen L, et al. Operating room teamwork among physicians and nurses: teamwork in the eye of the beholder. Journal of the American College of Surgeons. 2006;202(5):746-52.

18. Rydenfält C, Johansson G, Larsson PA, Åkerman K, Odenrick P. Social structures in the operating theatre: how contradicting rationalities and trust affect work. Journal of Advanced Nursing. 2012;68(4):783-95.

19. Thomassen Ø, Brattebø G, Heltne J-K, Søfteland E, Espeland A. Checklists in the operating room: Help or hurdle? A qualitative study on health workers' experiences. BMC health services research. 2010;10(1):1-6.

20. Rydenfält C, Johansson G, Odenrick P, Åkerman K, Larsson PA. Compliance with the WHO Surgical Safety Checklist: deviations and possible improvements. International Journal for Quality in Health Care. 2013;25(2):182-7.

21. Eriksson K. Becoming through sufferingthe path to health and holiness. International Journal of Human Caring. 2007;11(2):8-16.

22. Eriksson K. Evidence: To see or not to see. Nursing Science Quarterly. 2010;23(4):2759.

23. Eriksson K, Åbo akademi. Enheten för v. Gryning III : vårdvetenskap och 
Krupic F. The influence of occupation and teamwork on the successful use of the WHO surgical checklist: experiences of Swedish healthcare professionals.

hermeneutik. 1. uppl. ed: Vasa : Enheten för vårdvetenskap, Åbo akademi; 2007.

24. Sweden Ro. Lag (2003:460) om etikprövning av forskning som avser människor Stockholm: Utbildningsdepartementett; 2003 [updated 2021:920. Available from: https://www.riksdagen.se/sv/dokumentlagar/dokument/svensk-

forfattningssamling/lag-2003460-ometikprovning-av-forskning-som_sfs-2003460.

25. (WMA) WMA. World Medical Association Declaration of Helsinki: ethical principles for medical research involving human subjects. Jama. 1964;310(20):2191-4.

26. Jakobsson U, Westergren A. Enkätmetodik - en svär konst. Vård i Norden. 2005;25(3):72-3.

27. Rönnberg L, Nilsson U. Swedish Nurse Anesthetists' Experiences of the WHO Surgical Safety Checklist. Journal of perianesthesia nursing. 2015;30(6):468-75.

28. O'Brien B, Graham MM, Kelly SM. Exploring nurses' use of the WHO safety checklist in the perioperative setting. Journal of nursing management. 2017; 25(6):468-76.

29. Sendlhofer G, Mosbacher N, Karina L, Kober B, Jantscher L, Berghold A, et al. Implementation of a surgical safety checklist: interventions to optimize the process and hints to increase compliance. PloS one. 2015;10(2):e0116926-e.

30. Erestam S, Haglind E, Bock D, Erichsen Andersson A, Angenete E. Changes in safety climate and teamwork in the operating room after implementation of a revised WHO checklist: a prospective interventional study. Patient Safety In Surgery, 2017, Vol 11. 2017;11.
31. Sexton JB, Makary MA, Tersigni AR, Pryor D, Hendrich A, Thomas EJ, et al. Teamwork in the operating room: frontline perspectives among hospitals and operating room personnel. The Journal of the American Society of Anesthesiologists. 2006;105(5):877-84.

32. Undre S, Sevdalis N, Healey AN, Darzi SA, Vincent CA. Teamwork in the operating theatre: cohesion or confusion? Journal of evaluation in clinical practice. 2006;12(2):182-9.

33. Skevington SM, Langdon JE, Giddins G. 'Skating on thin ice?'Consultant surgeon's contemporary experience of adverse surgical events. Psychology, health \& medicine. 2012;17(1):1-16.

34. Keijzer WW, Agha RA, Greig A. WHO Safer Surgery checklist compliance amongst paediatric emergency plastic surgery patients in an UK hospital. Annals of medicine and surgery. 2017;21:49-52.

35. (GSC) GSC. Pooled analysis of WHO Surgical Safety Checklist use and mortality after emergency laparotomy. Journal of British Surgery. 2019;106(2):e103-e12.

36. Lingard L, Regehr G, Orser B, Reznick R, Baker GR, Doran D, et al. Evaluation of a preoperative checklist and team briefing among surgeons, nurses, and anesthesiologists to reduce failures in communication. Archives of surgery. 2008;143(1):12-7.

How to cite this article: Krupic F. The influence of occupation and teamwork on the successful use of the WHO surgical checklist: experiences of Swedish healthcare professionals. Int $J$ Health Sci Res. 2021; 11(12):31-41. DOI: https://doi.org/10.52403/ijhsr.20211205 